\title{
Programas de respiro en el domicilio y acompañamiento a las personas cuidadoras primarias, una estrategia clave para humanizar la relación de cuidados en el ámbito familiar: el caso de Alkar Zaintzen
}

\author{
Karin Yancen Rojas \\ Psicóloga, Máster en Investigación consultoría e Innovación Social, \\ Orue Auzolana Fundazioa \\ kyancen@deusto.es
}

\begin{abstract}
Artikuluak Alkar Zaintzen programak etxean duen eragina aurkezten du lagun egitearen ikuspegitik, lehen-mailako zaintzaileen bizi-kalitatearekin lotutako aldagaietan, hala nola, parte-hartze soziala hobetzea, familiaren lasaitasuna eta autonomiaren alde egitea. Horrez gain, erakusten du nola mendekotasuna duen pertsonaren ebaluazio integrala txertatzea eta norberaren autonomia mantentzea helburu duen arretaplanaren diseinua oinarrizko direla lehen-mailako zaintzailearen bizitza-kalitate handiagoa lortzeko. Modu honetan, bi pertsonen laguntza-harremana integratzen da. Programak mendekotasun-egoeran dagoen pertsonaren autonomia mantentzeko duen intzidentzia ere aurkezten da.
\end{abstract}

\section{GAKO-HITZAK:}

Lehen-mailako zaintzaileak, atseden-programak, etxez etxeko laguntza, lagun egitea, bizitzakalitatea, autonomia.
Este artículo presenta la incidencia que tiene Alkar Zaintzen, un programa de respiro en el domicilio desde la perspectiva del acompañamiento, en variables relacionadas con la calidad de vida de las personas cuidadoras primarias, tales como la mejora de la participación social, la tranquilidad familiar y el aumento de la autonomía. Además, muestra cómo la incorporación de una evaluación integral de la persona con dependencia y el diseño de un plan de cuidados orientado a mantener su autonomía personal es parte fundamental en el logro de esa mayor calidad de vida de la persona cuidadora primaria. Se integra de este modo el acompañamiento a ambas personas en la relación de cuidados. Se presenta también la incidencia del programa en el mantenimiento de la autonomía de la persona con dependencia.

\section{Palabras Clave:}

Cuidadores primarios, programa de respiro, atención domiciliaria, acompañamiento, calidad de vida, autonomía. 


\section{Introducción}

Escribimos este artículo con la intención de aportar, desde nuestra experiencia con la gestión de programas de atención a personas cuidadoras primarias o familiares, el conocimiento que hemos sistematizado con el programa de respiro en el domicilio Alkar Zaintzen -implementación, evaluación y seguimiento-y su incidencia en las personas participantes.

En este momento en que estamos afectados por la pandemia de la covid-19, hemos observado la dificultad de dar respuestas rápidas y eficientes desde el modelo de cuidados de larga duración actual. Por una parte, los fallecidos en residencias geriátricas hasta el mes de septiembre de 2020 habrían sido 20.476 personas, lo que significa $64,77 \%$ del total de las muertes notificadas oficialmente por el Ministerio de Sanidad de personas con coronavirus (rtve.es, 2020).

Por otra parte, desde el inicio del confinamiento en el mes de marzo, muchos servicios de atención a domicilio, servicios comunitarios y centros de día han cerrado o han tenido que limitar sus servicios para reducir los riesgos de contagio. Finalmente, muchos cuidadores y cuidadoras informales o precarios han quedado sin trabajo y sin la posibilidad de recurrir a los incentivos y apoyos públicos para complementar sus ingresos.

En este contexto, las familias quedaron aisladas en sus hogares y de un día para otro reabsorbieron todo el trabajo doméstico y de cuidados que durante las últimas décadas habían ido externalizando a través de distintos tipos de servicios, tanto públicos como privados. La importancia de los empleos de cuidados se hizo más visible que nunca mientras los hogares readaptaban cómo podían su organización de los cuidados (Moré, 2020).

En esta situación las personas cuidadoras, principalmente mujeres, confinadas en casa, son las que se han encargado de manera casi exclusiva de estas tareas, sin apoyo externo ni actividades de respiro. En un principio, en el momento más duro del confinamiento el programa de respiro Alkar Zaintzen pasa de la modalidad presencial al seguimiento en remoto con llamadas telefónicas y video llamadas.

Posteriormente, una vez iniciada la fase 3 de desconfinamiento en el mes de junio y cumpliendo normas de bioseguridad recomendadas por las autoridades, se inicia la atención en los domicilios. Nos encontramos con diversas reacciones, expresadas como angustia y temores ante la incertidumbre, pero sobre todo expresiones de profundo agradecimiento por el acompañamiento continuo y el inicio de las actividades con sus familiares con dependencia.

Envejecer en el domicilio, prolongar los cuidados en el domicilio, más que un deseo es la expresión de la necesidad de mantener una adecuada calidad de vida el mayor tiempo posible; esta crisis acelera este deseo dadas las grandes dificultades que en principio se presentaron en los centros residenciales. Sin embargo, no debemos perder de vista que cuidar en casa tiene un elevado coste social (Fernández, 2020).

Es necesario revisar posibilidades y servicios que prioricen la permanencia en el domicilio, pero con un adecuado acompañamiento y atención profesional tanto para la persona con dependencia como para la persona cuidadora primaria que suele ser un familiar en el $88,4 \%$ de los casos (Centro de Investigaciones Sociológicas, 2014).

Una alternativa que puede insertarse dentro de una red de cuidados desde el domicilio y la comunidad y que complementa las prestaciones de atención en centros de día o atención residencial son los programas de respiro en el domicilio, gestionados en este momento por organizaciones del Tercer Sector que ofrecen un servicio público, con financiación y regulación públicas.

En Bizkaia, estos programas surgen con el apoyo del gobierno foral (BOB, 14/2007) que desde el año 2012 a través del Departamento de Acción Social estudia modalidades de atención que faciliten respiros sin que la persona mayor con dependencia deba desplazarse de su domicilio. Es así como da los primeros pasos hacia la creación de un programa de respiro para personas que cuidan de mayores con dependencia y de esta forma completar los subprogramas existentes dentro de Zainduz.

Para cumplir con este objetivo, se contactó con organizaciones del Tercer Sector, entre las que destaca en primer lugar Cáritas Diocesana de Bilbao, con la que se lleva adelante el programa Esku-Onetan, proyecto de respiro para personas que cuidan a familiares dependientes en su propio domicilio (elcorreo.com, 2012).

El objetivo principal de este tipo de programas es ofrecer apoyo en su propio domicilio a las familias con personas dependientes, proporcionándoles "tiempos de respiro" en determinados momentos, a través de la acción de personas voluntarias o contratadas. Esto posibilitaría que la persona cuidadora sienta más apoyo en el cuidado, permitiendo una mejor calidad de vida mediante la ayuda de personal profesional y voluntario (Diputación Foral de Bizkaia, 2014)

Otra organización que presenta un programa de respiro y que cuenta con esta línea de apoyo de la Diputación Foral de Bizkaia es Orue Auzolana Fundazioa, con el programa Alkar Zaintzen, servicio de respiro integral en el domicilio para personas cuidadoras de personas con dependencia (Diputación Foral de Bizkaia, 2014)

Resaltamos con esta información que la idea de mantener y fortalecer las ayudas a las familias que 
presentan situaciones vulnerables como vivir con un familiar con dependencia siempre ha estado en el foco de las autoridades. Dada la nueva crisis de los cuidados generada por la covid-19, prolongar la permanencia en el hogar parece ser hoy una de las apuestas más importante de la Diputación Foral de Bizkaia, junto con centros residenciales lo más parecidos a un hogar y formación a profesionales sanitarios para mejorar la asistencia que prestan y la remuneración que reciben. También propone un cambio de modelo en los servicios sociales, que incluya "un sistema de apoyos y cuidados en el hogar basado en la tecnología, con monitorización permanente y combinado con servicios especializados en un centro de referencia próximo al domicilio que incorpore cuidados sociales y sanitarios y dirigido a las personas cuidadas y, también, a las personas cuidadoras" (declaraciones del diputado general Unai Rementeria).

Del mismo modo, contar con un sistema de apoyos tecnológico en el domicilio es una excelente vía de atención si se considera igualmente la atención a las personas cuidadoras primarias tomando en cuenta prácticas existentes dirigidas a mejorar la calidad de vida y el bienestar de las personas cuidadoras.

Una de estas prácticas son los programas de respiro en el domicilio, cuya sistematización aporta conocimiento en indicadores de gestión que luego pueden utilizarse en otras modalidades de atención integral, dirigidas a la atención de las necesidades tanto de la persona con dependencia como de la persona cuidadora.

En este artículo se presenta la sistematización de uno de estos programas. En primer lugar, se contextualiza la intervención y se describen brevemente los servicios disponibles en el sistema de atención a la dependencia para las personas cuidadoras primarias en Bizkaia, siendo los programas de respiro uno de estos servicios disponibles. Luego se explica la perspectiva del acompañamiento en este tipo de programas y se presenta el caso del programa Alkar Zaintzen.

El penúltimo apartado hace referencia a la crisis de la pandemia de la covid-19 y la respuesta que da el programa Alkar Zaintzen para garantizar la continuidad de atención domiciliaria en medio de las medidas de confinamiento durante los meses de marzo, abril y mayo de 2020 . Finalmente, se concluye la importancia de este tipo de programas de respiro en domicilio en el mantenimiento de las personas con dependencia en su hogar, así como la aportación que su sistematización puede brindar en el diseño de propuestas innovadoras de atención a la dependencia.

\section{Contextualizando la intervención}

Al hablar de cuidadores primarios nos referimos a aquellos que brindan cuidados desde la esfera de las relaciones primarias tanto familiares como no familiares de convivencia, amistad, vecindad o reconocimiento (Fantova, 2018). Estos cuidadores suelen dedicar la mayor parte de su tiempo a atender las necesidades de una persona dependiente (Dwyer et al., 1994).

Por lo general, la persona cuidadora primaria, que es quien asume las principales tareas del cuidado y las responsabilidades que estas implican, es percibida por los restantes miembros de la familia como la responsable del cuidado de la persona con dependencia, no es remunerada económicamente y lleva un tiempo prolongado cuidando de su familiar (Wilson,1989).

De acuerdo con los datos recogidos en la investigación que estamos realizando en Bizkaia, las personas cuidadoras primarias son un $77,9 \%$ de mujeres y un $\mathbf{2 1 , 2} \%$ de hombres. El vínculo de estas y estos cuidadores con la persona que necesita cuidados para realizar actividades de la vida cotidiana es: $35,6 \%$, mujeres cuidando al marido; $24 \%$, hijas cuidando a su madre; $14,4 \%$, maridos cuidando a su mujer; 3,8\%, madres cuidando a su hija; y 22,2\%, otros vínculos.

Las personas que asumen el cuidado de un familiar dependiente son descritas habitualmente como el paciente oculto o desconocido que requiere de un diagnóstico temprano de su situación y una intervención inmediata, debido a que están expuestas continuamente a una gran sobrecarga tanto física como mental (Flores et al., 2012).

Cuidar a un familiar con dependencia normalmente significar un cambio importante en la vida de la persona cuidadora, que suele experimentar falta de tiempo, agotamiento, relaciones familiares tensas, disminución o baja calidad de las relaciones sociales fuera de la familia y elevado estrés. Estos cambios traen con el tiempo una repercusión negativa en su salud (Pérez et al., 2017) y hacen aparecer un conjunto de problemas físicos, mentales y socioeconómicos a los cuales se denomina "síndrome del cuidador".

Este síndrome se caracteriza por la presencia de cansancio persistente, problemas de sueño, disminución o abandono de las aficiones, desinterés por vivir nuevas experiencias, elevada irritabilidad, dolores o molestias sin tener ningún problema de salud aparente, aislamiento social, consumo de ansiolíticos y/o antidepresivos, y niveles de estrés y/o ansiedad elevados (Villamar, 2014).

Cada síntoma referido es producto de la incidencia que una situación compleja como cuidar de una persona con dependencia tiene sobre las dimensiones fundamentales de la vida de una persona cuidadora, que son la salud física, la salud psicológica, las relaciones sociales y familiares, la vida laboral y/o el desarrollo profesional, la economía y el tiempo libre y de ocio (Rubio y Madariaga, 2013). 
Las dimensiones mencionadas componen las áreas del ciclo vital de las personas y promover su desarrollo integral es lo que garantiza que una persona se sienta empoderada y feliz (León, 2014), Ese desarrollo en el caso de las personas cuidadoras se ve afectado por un desequilibrio que está presente en la forma en que los cuidados se están gestionando en la sociedad.

Cuidar es parte de la vida, y garantiza su continuidad y sostenibilidad a lo largo de ese ciclo vital. Carrasco (2014-2015: 52) señala que es la vulnerabilidad física y psíquica de las personas, mujeres y hombres de todas las edades y condiciones lo que nos hace absolutamente interdependientes y nos obliga a establecer relaciones mutuas de cuidados. Afirma además que desde que nacemos, el trabajo de cuidados nos permite crecer, socializarnos, adquirir un lenguaje, unos valores y una identidad y autoestimas básicas, estando presentes aspectos afectivos y relacionales que nos permiten definir a los cuidados como bienes relacionales

De acuerdo a Ramírez Carro (2012), los bienes relacionales son aquellos que solo puedo "poseer" en un acuerdo con otro; aquellos bienes que tienen componentes afectivos y comunicativos; aquellos bienes que no tienen un precio de mercado sino que son valorados porque responden a una necesidad subjetiva de interacción, aquellos bienes que son coconsumidos y coproducidos al mismo tiempo por los sujetos involucrados; aquellos bienes que solo pueden ser disfrutados en la medida en que involucren potencial de reciprocidad; aquellos bienes en que la relación, por sí misma, constituye un bien. La definición de Ramírez Carro deja claro que los cuidados son bienes relacionales, pero también menciona que son aquellos bienes que solo pueden ser disfrutados en la medida en que involucren la reciprocidad. Esta reciprocidad es esencial, por lo que debe darse un equilibrio en el reparto de las tareas emocionales relacionadas con el vínculo y la preocupación por el otro (Brovelli, 2019).

Desde los aportes de la economía feminista se señala que este equilibrio necesario no se ha alcanzado y en su lugar estamos inmersos en la denominada "crisis de los cuidados", en la cual se evidencia una agudización de las dificultades de amplios sectores de la población para cuidarse, cuidar o ser cuidados. Dichas dificultades se manifiestan a raíz de una desestabilización del modelo tradicional de reparto de las responsabilidades sobre los cuidados y una reestructuración del conjunto del sistema socioeconómico, sin que se haya alterado por ello la división sexual del trabajo en los hogares ni la segmentación de género en el mercado laboral (Ezquerra, 2012).

En España, según la comparación entre la encuesta del empleo del tiempo de 2003 y la de 2010 (INE, 2010) Las diferencias existentes en el empleo del tiempo de hombres y mujeres continúan siendo significativas. Aunque la participación de las mujeres en el trabajo remunerado ha aumentado tres puntos y el de los hombres ha disminuido cuatro, aún hay más de diez puntos de diferencia entre la participación masculina y la femenina en esta actividad $(38,7 \%$ y $28,2 \%$, respectivamente). Además, el tiempo medio diario dedicado al trabajo remunerado por los hombres supera en más de una hora al de las mujeres.

Por el contrario, aunque la participación masculina en las tareas domésticas (actividades de hogar y familia) ha aumentado en los últimos siete años en casi cinco puntos y el porcentaje de mujeres dedicadas a las tareas del hogar ha disminuido menos de un punto, sigue habiendo una diferencia de participación en el trabajo no remunerado de diecisiete puntos porcentuales a cargo de las mujeres (74,7\% los hombres y $91,9 \%$ las mujeres).

Los datos también señalan que en el corto periodo de siete años, el tiempo dedicado en los hogares al cuidado no remunerado ha aumentado un $47 \%$. Este enorme aumento se debe a varias causas: envejecimiento, mayor proporción de jubilados, desempleo, restricción de servicios públicos y rentas familiares, corrección política respecto al reparto de las cargas domésticas entre mujeres y hombres que conlleva un aumento del número declarado de horas dedicadas al hogar, y aumento real de la participación de los varones, especialmente de los jubilados y los jóvenes.

Hay una sobrecarga en los hogares que se evidencia en ese aumento del $47 \%$ de tiempo dedicado al cuidado no remunerado. No está remunerado, pero como todo trabajo, implica tiempo, conocimientos y relaciones sociales complejas. Su especificidad es la de estar basado en lo relacional, y su carácter obligatoria y pretendidamente desinteresado y amoroso le otorga una dimensión moral y emocional marcada por la relación de servicio y asistencia (Hochschild, 2012).

El tiempo aparece como un recurso necesario para realizar todas las tareas relacionadas con cuidar de otros y de nosotros mismos, y debemos disponer de ciertas cantidades de este para organizarnos adecuadamente. Pero el tiempo no es un bien infinito, disponemos de solo veinticuatro horas diarias, por lo que solemos solapar tareas o, simplemente, tener poca disponibilidad para hacer otras.

Según refiere Durán (2017), la escasez de tiempo y el sentido de pobreza de tiempo disponible son más acusadas en las mujeres que en los varones. La disponibilidad de tiempo para sí mismas es mínima en las mujeres de edades centrales debido a su doble jornada, y la diferencia entre el tiempo disponible para sí mismos entre hombres y mujeres es máxima en las edades avanzadas, porque el hombre abandona el mercado de trabajo sin incorporarse plenamente a la producción de servicios en los hogares. 
Esta diferencia de disponibilidad en edades avanzadas no solo se debe a la falta de incorporación del varón a la producción de servicios en el hogar, sino que son en su mayoría hombres en edades avanzadas los que requieren de los cuidados en el hogar y este es suministrado principalmente por mujeres de la familia, principalmente su cónyuge. En edades más avanzadas son los hombres los que están comenzando a incorporarse al cuidado principalmente de sus mujeres, tal como muestran los datos recogidos en el trabajo de nuestra tesis doctoral.

La calidad de vida de los cuidadores primarios que cuidan a un familiar o persona en situación de dependencia está sujeta a diferentes limitaciones o barreras estructurales que limitan su posibilidad de desarrollar un proyecto de vida personal que esté claramente diferenciado de lo que implica cuidar de otro. En este sentido, Durán (2017) indica que las condiciones materiales de la existencia son muy importantes, pero no lo son menos otras condiciones como la disponibilidad de suficiente tiempo para la vida personal, el sentido de pertenencia, la posibilidad de hablar libremente con amigos o familiares y el sentimiento de sentirse querido.

Por consiguiente, resulta primordial avanzar hacia una responsabilidad social del cuidado y no verlo como un asunto privado que cada uno debe resolver como pueda. Hay que implicar la dimensión estatal, así como espacios comunes no estatales, mediante un diálogo abierto y continuo que establezca la vulnerabilidad como vínculo del cuidado (Mesto, 2018).

En este diálogo abierto como organización del Tercer Sector, Orue Auzolana Fundazioa busca crear un espacio de apoyo que incremente la disponibilidad de tiempo de las personas cuidadoras primarias de una persona con dependencia en su domicilio, a través de la gestión de un programa de respiro en el domicilio, brindándoles la posibilidad de mejorar su calidad de vida, sus relaciones interpersonales y sentirse valorados en su tarea de cuidar.

\section{Servicios disponibles en el sistema de atención a la dependencia para las personas cuidadoras primarias en Bizkaia}

\footnotetext{
En España, la aprobación de la Ley 39/2006 de Promoción de la Autonomía personal y Atención a las Personas en situación de Dependencia dio reconocimiento al derecho subjetivo que se fundamenta en los principios de universalidad, equidad y accesibilidad, desarrollando un modelo de atención integral a la persona en dependencia. Con esta propuesta legislativa se pretendía potenciar los servicios sociales para hacer que el cuidado familiar se convirtiera en algo excepcional. Sin embargo, en la aplicación práctica del sistema de atención a la dependencia, la realidad ha sido otra (Carral, 2015).
}

Los servicios sociales originalmente pensados para sostener el cuarto pilar del Estado de Bienestar han quedado en cierta forma relegados a un segundo plano. Parecen estar actuando como soporte de la familia como proveedor principal dado un modelo que según Daly y Lewis (citados en Carral, 2015) se ha fundamentado en el "catolicismo social" filosofía que se encuentra presente, en diferentes grados, en todos los Estados de Bienestar de la Europa continental y meridional (a excepción de los países escandinavos).

La principal consecuencia de esto es que se da lo que Sarraceno (citado en Carral, 2015) llama "familismo", que define como una confianza permanente en la familia, en su solidaridad intergeneracional y en su estructura tradicional de género, como proveedora de trabajo y servicios asistenciales y como integradora de medidas inadecuadas de apoyo a los ingresos.

Así, la gestión de los cuidados se continúa dando principalmente en la familia, a pesar del gran paso dado con la promulgación de la llamada Ley de Dependencia, y es desempeñado por aquel miembro de la familia que se encuentra en situación de vulnerabilidad psicosocial, siendo las mujeres las que han cumplido este rol con mayor frecuencia (Brovelli, 2015).

El esfuerzo que supone, tanto considerando la carga objetiva (tareas específicas que "por definición" conllevan actividades y tiempos) como la subjetiva (percepción y opiniones al respecto) es elevado. Con el fin de favorecer el bienestar de los cuidadores familiares de personas con dependencia en esta provincia y dentro del servicio de apoyo a personas cuidadoras que se encuentra recogido como un servicio social de atención primaria dentro del Catálogo de Prestaciones y Servicios del Sistema Vasco de Servicios Sociales, de acuerdo a lo establecido en el artículo 22.1.4 de la Ley 12/2008 de 5 de diciembre, de Servicios Sociales, los servicios y prestaciones que contemplan las Administraciones Públicas son (Rubio y Madariaga, 2013):

a. Servicio de Ayuda a Domicilio (SAD), destinado a "mantener en su domicilio habitual a las personas con dificultades, debido a limitaciones físicas, psíquicas y sensoriales, que hayan sido valoradas como dependientes en alguno de los grados previstos en la Ley 39/2006, de 14 de diciembre, de Promoción de la Autonomía Personal y Atención a las personas en situación de dependencia” (Imserso, 2012: 505). La legislación de este servicio se basa en la ordenanza municipal del ayuntamiento vizcaíno competente.

b. Centros de día para personas mayores dependientes. Estos centros diurnos establecen programas individualizados a personas mayores de sesenta años (o aquellas menores de esta edad pero que previo informe de la Comisión Técnica de Valoración de Personas Mayores, puedan equipararse a las personas de sesenta años o más) que necesiten ayuda para realizar sus actividades de la vida cotidiana. 
c. Residencias para personas mayores dependientes en estancia temporal. Ofrecen "una alternativa de respiro temporal a las familias, o personas cuidadoras de personas mayores dependientes, de forma que dicha familia o personas cuidadoras puedan seguir atendiendo y manteniendo a la persona mayor en su medio" (Imserso, 2012: 508) durante una estancia mínima de quince días y un periodo máximo de tres meses, exceptuando si está motivada por el periodo vacacional del cuidador, y otras situaciones reguladas.

d. Además de estos servicios de apoyo formal o de respiro, también existe un programa denominado Zainduz, dirigido exclusivamente a personas mayores dependientes y a sus familias en el ámbito geográfico de Bizkaia. Puede clasificarse como un programa en el que se combinan distintos tipos de estrategias: intervenciones de carácter educativo o psicoeducativo, programas de autoayuda o ayuda mutua, e intervenciones psicoterapéuticas o counseling y multicomponente.

Además de los servicios mencionados, también se han diseñado y ofrecen los programas de respiro en domicilio. Estos programas, al igual que los del SAD se prestan en el domicilio, pero a diferencia de este se atiende por periodos de tiempo más largos y además se incorpora la atención a la persona cuidadora como parte fundamental en el cuidado. En relación con los centros de día o estancias residenciales para el respiro de los cuidadores, la diferencia principal es ofrecer el tiempo de respiro con la posibilidad de que la persona con dependencia permanezca en su domicilio.

El programa de respiro Alkar Zaintzen de Orue Auzolana Fundazioa ofrece tiempos de respiro y acompañamiento para las personas cuidadoras primarias mientras su familiar con dependencia es atendido por un profesional en su domicilio. En la crisis sanitaria producto de la pandemia se registraron cero contagios tanto de la persona cuidadora como de su familiar con dependencia, por lo que intuimos que este contexto puede haber sido un espacio de mayor protección.

Este tipo de programa de respiro en el domicilio puede incidir en la mejora de la autonomía y de la calidad de vida a través del incremento de tiempo para las personas cuidadoras primarias, ofreciéndoles la oportunidad de disponer espacios para su vida personal, mejorar sus relaciones interpersonales $\mathrm{y}$, por tanto, el fortalecimiento de su proyecto de vida personal, todo ello con la tranquilidad de confiar en una atención profesional a

\section{Programas de respiro desde la perspectiva del acompañamiento y la gestión en red colaborativa}

En primer lugar, hay que definir a qué hace referencia la perspectiva del acompañamiento. A este respecto hay dos visiones convergentes: por una parte, el acompañamiento propio de una organización católica que trasciende fronteras como Cáritas, y, por otra, una visión de inspiración ignaciana. El acompañamiento es un pilar en los procesos de aprendizaje de la Compañía de Jesús, también católica. Ambas han demostrado una gran flexibilidad en la aplicación de su visión en cuestiones tan empresariales como el liderazgo o la gerencia (Lowney, 2004), así que partiendo de estas definiciones hemos incorporado esta estrategia en el programa de respiro Alkar Zaintzen de Fundación Orue.

En el proceso pastoral católico, el acompañamiento no es un término de moda, sino que expresa una forma de actuación que recoge la desarrollada por Jesucristo, tal como aparece en los evangelios. Con ella se expresa una actitud de escucha y de cercanía a todo hombre y a toda mujer, esté en la situación en la que esté, y sea cual sea su situación vital. Así lo recogen los numerosos ejemplos de las relaciones que Jesús lleva a cabo a lo largo de su vida pública, o se refleja en las parábolas que él cuenta (Ávila, 2018).

Para Martínez Ruipérez (2013: 9) en el curso 2008/2009 se empieza a gestar la idea de sistematizar el proceso de acompañamiento en los programas de Cáritas en España, con la finalidad de compartir un espacio de reflexión y aprendizaje que llevase a concretar las experiencias vividas y el recorrido formativo compartido. Definir qué se entiende por procesos de acompañamiento para el desarrollo integral de cada persona como impulso para la responsabilidad, la participación, la emancipación y la incorporación social.

La aproximación que se hace a cada persona atendida por Cáritas debe ser una manera de estar al lado de, que lleva a una toma de conciencia y a un cambio de mirada y de posición personal y ver al otro ser como un ser sagrado (Martínez Ruipérez. 2013: 10). Esta mirada exige una combinación de ciencia y arte, de rigor y creatividad, de razón y corazón. En esta forma de acción son formados todos los profesionales y voluntarios en esta organización.

En la explicación del proceso de acompañamiento queda claro que las palabras acompañar, acompañamiento integral o proceso son referencias constantes en el modelo de acción social de Cáritas Española, y se suelen utilizar para describir el compromiso con las personas en situación de vulnerabilidad o exclusión social para facilitar que superen sus dificultades.

Para tener un conocimiento más claro de este proceso, en el Cuadro 1 se resume lo que es el acompañamiento diferenciándolo de lo que no lo es. 


\section{ACOMPAÑAR/NOS ES}

Una relación vital entre personas

Ir al lado, compartir un camino común

Estar en un plano de mutuo apoyo, de cuidado, en una relación horizontal

Abrir la mirada, la escucha, la comprensión

Orientar, motivar, ofrecer nuevas perspectivas, nuevos caminos

Un arte

Un caminar descubriendo, aprendiendo juntas

\section{ACOMPAÑAR/NOS NO ES}

Establecer una relación terapéutica

Realizar un seguimiento

Dirigir

Aconsejar

Decidir sobre su situación o proceso

Aplicación "sin alma" de una técnica Una tutela

Fuente: Cuadernos de formación. Acción Social. El arte de acompañar/nos, procesos y metodologías (2013).

De este resumen se puede concluir que acompañar es un diálogo permanente, no impositivo, que integra la experiencia de la persona como parte del diálogo, siendo ella la que toma sus propias decisiones en el proceso, desde un clima de empatía, escucha activa alejado de las nociones de seguimiento y tutelaje.

El acompañamiento al estilo ignaciano, por su parte, guarda total similitud con estas ideas expuestas, pero a diferencia de la construcción inicial a partir del intercambio con las comunidades, el proceso de acompañamiento ignaciano proviene de los Ejercicios Espirituales de san Ignacio de Loyola, cuando se refiere a "la persona que da a otro, modo y orden para meditar o contemplar" (Arroyo Lewin y Bermúdez García, 2020).

El acompañamiento desde una mirada estrictamente ignaciana se refiere a "acompañar a otras personas para que descubran la voluntad de Dios en su vida y en el análisis de la realidad". Para esto, complementa Zatyrka (citado en Velasco, 2018), es necesario echar mano del llamado "sentir ignaciano", que tiene tres referentes principales: el intelectual, ya que no se puede orientar sin entender; el afecto, ya que no solo basta entender, sino querer; y la paz y la armonía interior. Estos tres factores, añade, son fundamentales en el momento de tomar decisiones.

Intelecto, afecto y paz, lo que podríamos interpretar como formarnos y conocer, activar el afecto para ser empáticos y estar en equilibrio. Con estos tres elementos como referentes, acompañar es estar con el otro, apoyándolo con amor en el encuentro consigo mismo. Situarse al lado del otro como compañero de camino, estableciendo relaciones de diálogo y amistad, relaciones de compañía que permiten crecer y compartir recíprocamente, sin que cada uno deje de ser lo que es (Ramírez García et al., 2004).

El proceso de acompañamiento es una metodología y una visión que está en la base de todo actuar en Cáritas y es igualmente parte fundamental de los procesos de aprendizaje y formación en la Compañía de Jesús. Partiendo de estos principios, un programa pionero en programas de respiro en domicilio con el acompañamiento como estrategia de apoyo a sus beneficiarios es el programa Esku onetan de Cáritas Bizkaia. Otro de los programas pioneros, aunque menos conocido que también sigue los principios del acompañamiento a sus beneficiarios es el programa Alkar Zaintzen de la Fundación Orue Auzolana, cuyo objetivo es igualmente proporcionar un servicio de horas de respiro semanales a las personas cuidadoras a la vez que la persona con dependencia es atendida en su domicilio siguiendo un plan de intervención personalizado atendido por diferentes profesionales formados en el área de servicios de cuidados.

Brindar atención con una visión centrada en el acompañamiento permite que tanto la persona cuidadora como la persona con dependencia sientan el apoyo en el encuentro, a través de una escucha atenta que valida la experiencia vital de cada uno. Se crean espacios de compañía que fortalecen las relaciones interpersonales de los participantes, además de que la persona cuidadora dispone de unas horas para invertir en diferentes actividades que favorecen su participación social, propician la tranquilidad familiar y aumentan igualmente la autonomía de la persona cuidadora primaria y su bienestar.

Otro elemento fundamental de este tipo de programas es contar con una gestión colaborativa con los servicios sociales de base en cada ayuntamiento. En primer lugar, para identificar a aquellos grupos familiares donde los cuidadores presentan un nivel de sobrecarga elevado. Y en segundo lugar, para mantener una comunicación fluida ante las diferentes situaciones que puedan presentarse con el fin de dar una respuesta eficiente e integral a las personas usuarias.

Desde este tipo de programa también se busca diseñar acciones orientadas a favorecer una mayor participación de la comunidad; en este sentido, la intervención directa de los profesionales que están en el domicilio busca mantener contacto directo con la red comunitaria informal. Todas estas relaciones con los ayuntamientos, los servicios de base y la comunidad son lo que se denomina "gestión en red colaborativa”, que va dirigida a crear y fortalecer el trabajo en red. 
5. Programas de respiro: Alkar

\section{Zaintzen, una experiencia en clave de acompañamiento}

En un sistema público de bienestar incapaz de proporcionar ligeros cuidados o apoyos domiciliarios preventivos (desde los servicios sociales) que, sin embargo, incurre posteriormente en altos gastos hospitalarios, farmacéuticos o tecnológicos, en buena medida inducidos por la ausencia de esa intervención social más temprana (Fantova, 2015), revisten especial interés las experiencias y modelos que promuevan la prevención y la permanencia el mayor tiempo posible en los hogares de las personas con dependencia, pero con la posibilidad de contar con servicios y apoyos adecuados.

Un tipo de programa que favorece esa permanencia en los hogares de las personas con dependencia y que a su vez brinda un apoyo necesario a las personas cuidadoras primarias es el programa de respiro en el domicilio, que garantiza atención profesional para ambas personas en la relación de cuidados. Es importante orientar a la familia de las personas con dependencia en la distribución de las tareas de cuidados y al mismo tiempo insistir en la importancia de disponer de espacios de autocuidado que sirvan para reducir la carga percibida como cuidador.

Alkar Zaintzen se crea como un servicio de respiro en el domicilio para cuidadores primarios de personas con dependencia. Además del respiro y el acompañamiento, proporciona a la persona con dependencia y a la persona cuidadora un plan de atención personalizada en su domicilio, algo que continúa siendo de difícil acceso para la mayoría de las personas en situación de dependencia y sus cuidadores.

Desde un punto de vista social y humano todas las personas son interdependientes y requieren de diferentes cuidados a lo largo de su vida (Carrasco et al., 2011); por este motivo, este servicio de respiro tiene una doble funcionalidad y busca conseguir paralelamente objetivos de mejora en la calidad de vida de la persona cuidadora y mantenimiento de la autonomía personal de la persona con dependencia (Orue Auzolana Fundazioa, 2013). Los objetivos generales dirigidos a la persona cuidadora son los siguientes:

1. Permitir descansar a la persona cuidadora unas horas semanales de su labor, priorizando la permanencia de la persona con dependencia en su entorno y/o domicilio habitual.

2. Acompañar y orientar a la persona cuidadora primaria en su tarea, con la consiguiente disminución de la sobrecarga de esta. El logro de este objetivo se alcanza mediante los siguientes objetivos específicos:

2.1. Favorecer el desarrollo integral de cada persona cuidadora orientándole en el uso y gestión de las horas de respiro, fomentando su autonomía personal.

2.2. Fomentar una buena relación y uso de los servicios de apoyo de los que dispone.

2.3. Generar un proceso de maduración individual que permita mejorar la gestión de los cuidados.

2.4. Acompañar en la reflexión del proyecto de vida de cada persona cuidadora participante y de la atención a su familiar con dependencia.

2.5. Brindar a la persona cuidadora, elementos que le posibiliten conocer mejor su realidad interior y exterior, de modo que pueda elegir en la vida con libertad, responsabilidad y autonomía.

3. Control y seguimiento de la sobrecarga del cuidador.

Por otro lado, como hemos mencionado anteriormente, consideramos que este servicio de respiro cubre indirectamente otras necesidades importantes, relacionadas con la persona con dependencia, como es garantizar la calidad de cuidados prestados por las personas cuidadoras en el domicilio.

4. Garantizar un seguimiento personalizado de la evolución de las personas con dependencia en el domicilio.

5. Garantizar una atención integral, integrada y de continuidad, promoviendo una mejor calidad de vida para ambos.

\subsection{Destinatarios y muestra inicial}

El proyecto está dirigido a personas cuidadoras de familiares con dependencia sin límite de edad, que conviven en el mismo domicilio, que asumen ser el cuidador principal, beneficiarias de la prestación económica por cuidados en el entorno familiar y que la persona con dependencia tenga una valoración de dependencia grado II o III.

En el año 2013, primer año del programa, participaron un total de 23 personas cuidadoras primarias; la selección se hace en colaboración con los Zainduz y los ayuntamientos (servicios sociales de base principalmente), los cuales identificaron a aquellas personas cuidadoras que presentaron la mayor sobrecarga en función de las valoraciones de sus equipos especializados.

Una vez identificadas las personas usuarias del programa, se realiza una presentación inicial y se planifican las sesiones de evaluación y resultados.

\subsection{Metodología de la intervención}

El programa ofrece a la persona cuidadora tres horas semanales de respiro y de acompañamiento por un psicólogo como profesional de referencia, mientras que la persona con dependencia es atendida por 
profesionales en su domicilio, principalmente fisioterapeutas y auxiliares de geriatría, el tipo de profesional dependerá de las necesidades observadas en cada persona con dependencia. Es un programa que utiliza una metodología de observación y seguimiento longitudinal, se recopilan datos de la misma muestra repetidamente en diferentes momentos del programa; a la entrada estableciendo una línea base, al cabo de un año de atención y posteriormente se continúan las mediciones anuales para valorar los cambios tanto de las personas cuidadoras como de las personas con dependencia a lo largo de su participación en el programa.

La línea base se obtiene en un proceso de evaluación integral que incluye, evaluación del contexto, la situación global de la persona con dependencia y el nivel de sobrecarga de la persona cuidadora. Esta evaluación se realiza en dos momentos:

1. Diagnóstico del contexto: entrevista abierta a la familia, conformada por una batería de preguntas para conocer: el tiempo que tienen cuidando, recursos de apoyo de los que disponen (instituciones, otros familiares, cuidadores contratados, etc.), enfermedades preexistentes, tiempo diario que dedican al cuidado, valoración subjetiva de su sobrecarga y bienestar personal y sus expectativas del servicio.

2. Evaluación global de la persona con dependencia y nivel de sobrecarga de la persona cuidadora: la evaluación global es un proceso dinámico y estandarizado orientado a detectar, describir y aclarar el nivel físico, funcional, psicológico y socioambiental que la persona con dependencia presenta.

Para la obtención de este indicador global se aplican un conjunto de escalas respaldadas por diversas investigaciones (D’Hyver, 2017; Fernández y Estévez, 2013; Montenegro et al., 2009) en la obtención de una valoración orientada a la identificación y explicación de los problemas del adulto mayor con dependencia. Se busca identificar las necesidades de servicios y desarrollar planes de cuidados focalizados en intervenciones para la mejoría funcional, mental, clínica, y social del adulto mayor y su familia (Montenegro et al., 2009).

Las valoraciones que se realizan son:

a. Información de historia médica y valoración del estado nutricional con la aplicación de la escala MNI, a través de la cual se evalúa el riesgo de malnutrición en la persona con dependencia, favoreciendo el desarrollo de intervenciones rápidas que beneficien el estado nutricional y que reduzcan las consecuencias de un mal aporte calórico-proteico.

b. Evaluación psicológica: esta se realiza para determinar trastornos de las funciones cognoscitivas y alteraciones de la esfera afectiva que repercuten negativamente en las actividades de la vida diaria. Se aplican las siguientes escalas:

- MEC (mini examen cognoscitivo de Lobo), que proporciona un análisis breve y estandarizado del estado mental.

- FAST (evolución funcional) y GDS (escala de deterioro global), que si bien se utilizan con mayor frecuencia para medir el deterioro funcional asociado al Alzheimer, sirven para tener un punto de referencia de la progresiva incapacidad de la persona con dependencia para el mantenimiento de las actividades básicas de la vida diaria.

- NPI (inventario neuropsiquiátrico): sirve para valorar los cambios de conducta experimentados en el transcurso de la enfermedad.

c. Evaluación social: explora el ajuste y el apoyo social. Se aplican las siguientes escalas:

- Gijón (valoración socio familiar): explora el riesgo social asociado a la situación familiar, situación económica, vivienda, relaciones sociales y apoyo de las redes sociales.

- OARS (escala de recursos sociales): Sirve para valorar el deterioro de los recursos sociales de las personas mayores con dependencia.

d. Evaluación funcional: permite conocer el desempeño en las actividades de la vida diaria, el cual es fundamental para dar sentido y orden a la vida de las personas. Las escalas utilizadas son:

- Barthel (índice de independencia/ dependencia para actividades de la vida) mide la capacidad de la persona para la realización de diez actividades básicas de la vida diaria, obteniéndose una estimación cuantitativa del grado de dependencia de la persona.

- Lawton y Brody (escala instrumental): permite conocer el grado de independencia que tiene la persona con dependencia para valerse por sí misma en la vida diaria, complementa los datos obtenidos con el índice Barthel.

- Tinetti (escala para el equilibrio y la marcha): mide el riesgo de caídas durante el año siguiente de su aplicación

e. Otros: para finalizar, se aplica la escala Charlson (índice de comorbilidad), con el objetivo de establecer las expectativas de vida de un paciente y de esta forma conocer posible evolución de las personas que atendemos.

Para conocer la situación de la persona cuidadora, además de la entrevista realizada en el momento inicial, se aplica la escala Zarit (sobrecarga del cuidador) para medir el grado de sobrecarga/ bienestar que tienen en el momento del inicio de su participación en el programa.

Una vez finalizado todo el proceso de evaluación, se diseña el plan de cuidados para la persona con dependencia, y se les presenta a la persona cuidadora y a la persona con dependencia siempre 
que esto sea posible. Las horas de aplicación del plan son las horas de respiro de las que dispone la persona cuidadora y el horario se establece de común acuerdo con el equipo del programa. Antes de iniciar formalmente el respiro, la persona cuidadora se compromete a aprovechar dichas horas en actividades dirigidas a su autocuidado que pueden ser descanso, visitas médicas, retomar relaciones interpersonales y participar en actividades de ocio.

La persona cuidadora cuenta a partir de ese momento con un profesional de referencia que la acompañará en el proceso de gestión de tiempo y en el proceso de reflexión acerca de la necesidad del autocuidado y de retomar un proyecto de vida personal.

\subsection{Resultados del programa en las personas cuidadoras primarias}

Desde el año de inicio en 2013 hasta la actualidad, se han beneficiado un total de 84 personas cuidadoras, 69 mujeres, lo que representa un $82 \%$, y 15 hombres, que representan el $18 \%$ de las personas beneficiadas. El promedio de edad por sexo es de 70 años para mujeres y de 69 años para hombres, con un periodo promedio de permanencia en el programa de tres años.

El vínculo principal entre la persona cuidadora y la persona en dependencia es de cónyuge, representando el $46,43 \%$ del total de personas

Tabla 1. Parentesco de la persona cuidadora por sexo y por municipio cuidadoras; 44,04\% son hijas e hijos cuidando a sus padres y un $10,71 \%$ son cuidadores de otros parientes (sobrinas, hermanas y nieto).

El 48,80\% de las personas cuidadoras han reportado no tener ningún problema de salud, siendo las enfermedades musculares $(16,67 \%)$ y anímicas $(14,28 \%)$ las más frecuentes entre los que mencionaron alguna enfermedad.

En cuanto a los cuidadores atendidos por municipio, el $47,61 \%$ han sido de la mancomunidad de Uribe Costa; el 33,33\% del municipio de Galdakao; el 15,47\% de Ermua; el 4,76\% de Santurtzi y el 2,38\% de Bilbao. En la Tabla 1 se detalla el número de personas cuidadoras por municipio, parentesco y sexo.

Al inicio del programa en el 2013, la medición que se realiza a las 23 personas usuarias en la escala de sobrecarga Zarit - cuyos valores de referencia indican que puntajes menores o iguales a 46 son no sobrecarga y que valores iguales o mayores a 56 indican sobrecarga intensa-. Da como resultado un valor promedio de 62 puntos, lo que indica que las personas cuidadoras tenían un nivel de sobrecarga intensa.

En la segunda medición que se realiza a las mismas personas al finalizar ese mismo año ya se observa un descenso de 13,1 puntos, por lo que el valor promedio ya se ubicaba en sobrecarga media. En los siguientes años se observan puntuaciones por debajo de 46, lo que ya indica niveles de no sobrecarga (ver Gráfico 1).

\begin{tabular}{|c|c|c|c|c|c|c|}
\hline & $\begin{array}{l}\text { Cónyuge } \\
\text { mujer }\end{array}$ & $\begin{array}{l}\text { Cónyuge } \\
\text { hombre }\end{array}$ & Hijo & Hija & $\begin{array}{c}\text { Otro } \\
\text { pariente }\end{array}$ & $\begin{array}{l}\text { Total por } \\
\text { municipios }\end{array}$ \\
\hline Bilbao & 1 & 1 & & & & 2 \\
\hline Ermua & 5 & 3 & 1 & 2 & 2 & 13 \\
\hline Galdakao & 10 & 1 & 1 & 15 & & 27 \\
\hline Santurtzi & 2 & & & & & 2 \\
\hline Uribe Kosta & 13 & 2 & 6 & 18 & 1 & 40 \\
\hline Total por tipo de vínculo & 31 & 7 & 8 & 35 & 3 & 84 \\
\hline
\end{tabular}

Fuente: Elaboración propia a partir de los datos en las memorias del programa desde el 2013 hasta el 2019.

Gráfico 1. Promedio anual Zarit

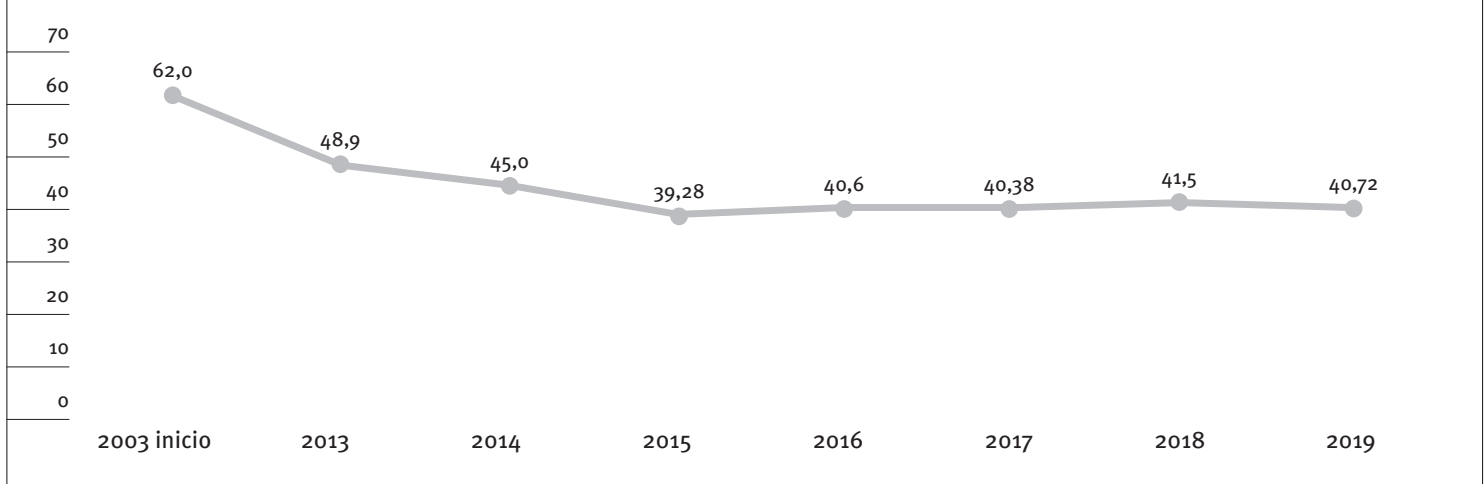

Fuente: Elaboración propia. 
Esto puede explicarse por una mayor disponibilidad de tiempo que han dedicado a atender su salud, mejorar el uso de su tiempo de ocio y descanso, así como contar con profesionales con quien hablary sentirse apoyados y valorados por estos.

Las 23 personas del año 2013 permanecieron todas hasta el final de ese mismo año, la permanencia de las personas va variando por diferentes situaciones, entre estas las más frecuentes son, muerte de la persona con dependencia, contratación de cuidadores internos o por horas, siendo las menos frecuentes la institucionalización de la persona con dependencia (estos datos los obtenemos de la movilidad anual de las personas en el programa).

Es importante señalar que cada persona cuidadora tiene una evaluación de entrada al programa y una segunda medida al completar un año de atención. En el gráfico reflejamos los índices Zarit promedios de las segundas mediciones al completar cada año la atención.

La satisfacción de las personas cuidadoras usuarias con el programa Alkar Zaintzen, se ha medido de manera cualitativa a través de una encuesta de preguntas abiertas orientadas a valorar su percepción con relación a la utilidad, calidad del servicio, beneficios para la persona con dependencia y sugerencias de mejora

El resultado medido de los últimos dos años (2018/2019) indica un $100 \%$ de acuerdo de valoración favorable entre 48 personas cuidadoras entrevistadas, en relación con los beneficios y la utilidad del programa, especificando los siguientes beneficios: tranquilidad familiar, incremento en la autonomía y aumento en su participación social (estos beneficios fueron mencionados por todas las personas cuidadoras entrevistadas esos años).

Hay también acuerdo del $100 \%$ en que el programa beneficia a sus familiares con dependencia en mejor movilidad, mayor estimulación, mejoras en su socialización y mejor ánimo. El 100\% menciona estar de acuerdo en querer continuar con el servicio y el $100 \%$ refiere que no han echado en falta nada en el programa. Finalmente, y de forma sistemática los últimos dos años, el elemento común a mejorar se refiere a aumentar el número de horas del respiro, incorporar turnos vacacionales y poder contar con el servicio algunos fines de semana.

\subsection{Resultados de personas con dependencia}

Desde el año de inicio en 2013 hasta la actualidad, se han beneficiado un total de 72 personas con dependencia; 33 mujeres, lo que representa un $45,8 \%$, y 39 hombres, que representan el $54,1 \%$ de las personas beneficiadas. El promedio de edad por sexo es de mujer de 87 años y hombre de 78 años, con un periodo promedio de permanencia en el programa de tres años.
Las personas con dependencia atendidas en el programa tienen valoraciones de dependencia grados 2 y 3 , siendo un $52,7 \%$ de grado 2 y el $47,3 \%$ de grado 3. El perfil de enfermedades de las personas con dependencia se observa en el Gráfico 2, e indica que el $30,8 \%$ presentan espondilitis anquilosante, el $20,58 \%$ hemiplejia y el $19,11 \%$ demencia vascular como patologías principales.

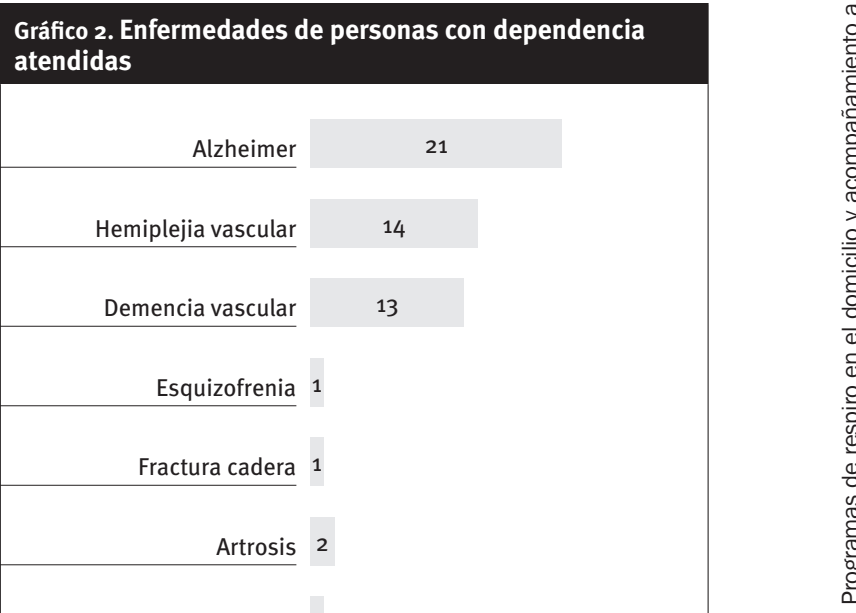

Para la valoración de los resultados de las personas con dependencia, presentamos dos cortes temporales de la intervención, el primero de 20132014/2014-2015 y 2015-2016 que representan 3 años de atención. El año 2017 fue un año de cambios en la coordinación, se mantiene la atención en el hogar, pero no se realizaron todas las evaluaciones de seguimiento, luego se retoman las mediciones longitudinales por lo que presentamos los resultados de 2018 a 2019, por lo que estos deben completarse con los que se obtengan al finalizar 2020 con posibles incidencias de la pandemia a valorar.

Los promedios de las escalas de valoración administradas en el año 2014 los comparamos con la valoración en 2016 de los mismos usuarios que se mantuvieron esos años. En el Gráfico 3 se observa que el funcionamiento social medido en las escalas 
de Gijon y OARS hay una mejora en 1,5 y 2 puntos, respectivamente, lo que parece indicar que la familia al percibir apoyo reduce el riesgo social para la persona con dependencia. En los indicadores de la situación funcional (Barthel, Lawton-Brody y Tinetti) se observan puntuaciones levemente superiores en la segunda medición. Sin embargo, ambas puntuaciones representan nivel de dependencia moderado-severo, lo que se corresponde con lo esperado para la edad de la persona con dependencia en el programa (78-87 años) el aumento en los puntajes puede explicarse por la mejora en algunas actividades de la vida diaria en forma puntual como realizar tareas ligeras, trasladarse y reducir su riesgo de caídas. Los valores en la aplicación en la escala MNA suben 4 puntos, pero en todo caso se mantienen dentro de la categoría bien nutridos en sus hogares

En el Gráfico 4 presentamos los promedios de las escalas de valoración administradas en el año 2018 y los comparamos con la valoración del año 2019. Se puede observar que el área social medida en las escalas Gijón y OARS ha disminuido en 1,71 y 5.28 puntos respectivamente, lo que refleja, de acuerdo con lo que miden las escalas bajo riesgo social para la persona con dependencia, los recursos de apoyo social que provienen de sus familiares se mantienen.
En cuanto a las escalas que indican el nivel de dependencia/autonomía, se observan puntajes más altos que indican que se pasa de la categoría de dependencia severa a moderada en el Barthel y lo mismo se observa en la escala Tinetti, un leve aumento en la gestión de actividades diarias tales como trasladarse y deambular pueden explicar estos resultados. Por su parte, los puntajes en la escala Lawton Brody se mantiene en la categoría de dependencia severa, ya que no logran gestionar actividades de la vida diaria un poco más complejas como marcar números telefónicos o administrar su economía. Su estado nutricional refleja mejores resultados que se relacionan con pasar de puntajes de riego a buen estado nutricional, pero no tenemos evidencias claras que expliquen este cambio.

Finalmente, en las escalas que indican el nivel de funcionamiento cognitivo (FAST, MEC y NPI) los puntajes se han incrementado lo que es reflejo de un deterioro cognitivo que cambia de un deterioro cognitivo moderado a severo con indicadores de alteraciones neuropsiquiátricas leves.

Estos resultados en dos momentos temporales del programa indican que hay evidencias de mejoría puntual en el perfil funcional, en los valores nutricionales y en el perfil social de la persona con

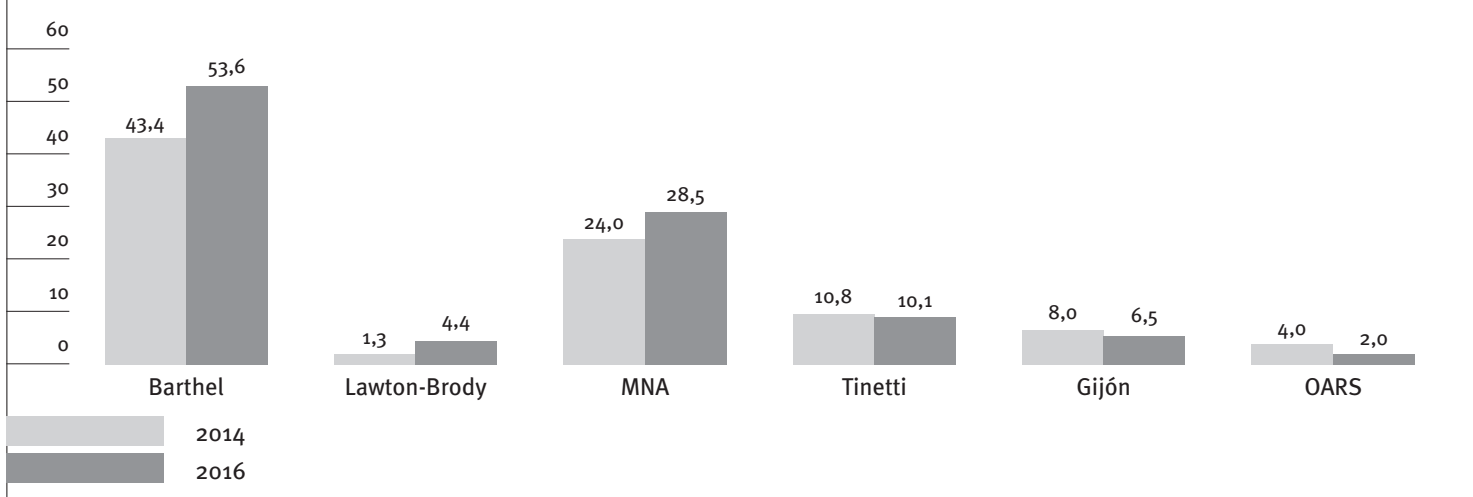

Fuente: Elaboración propia.

Gráfico 4. Perfil de evaluación funcional 2018-2019 (promedios)

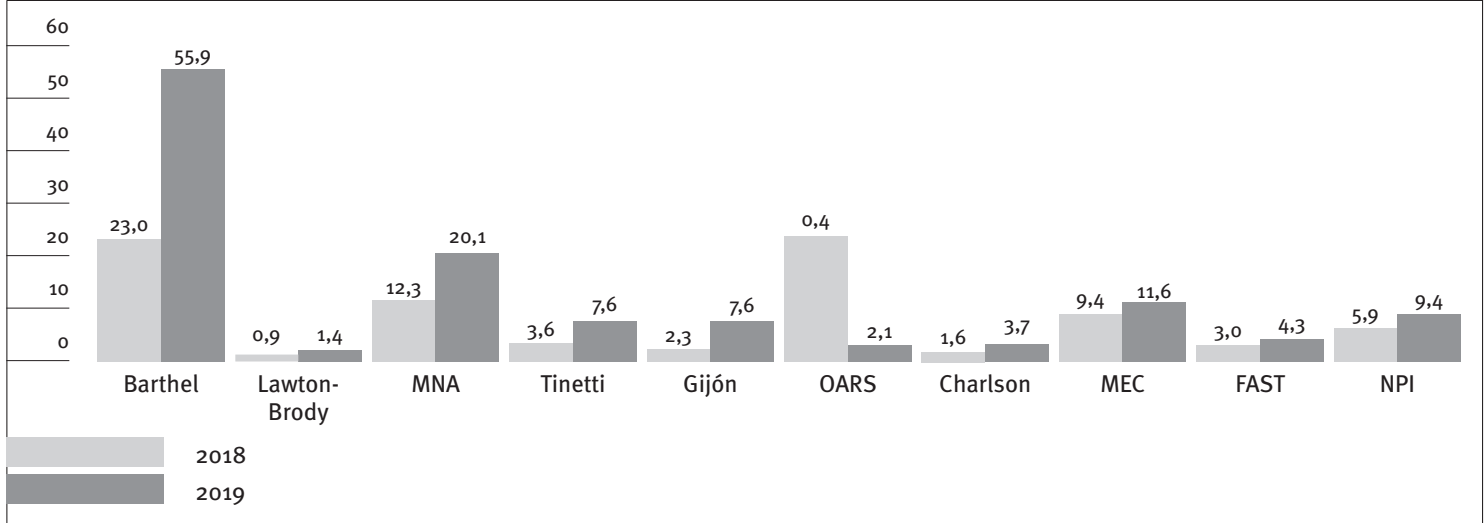

Fuente: Elaboración propia. 
dependencia. Sin embargo, el deterioro cognitivo y el leve aumento en el índice Charlson reflejan deterioro en estas áreas lo cual es esperado en adultos mayores con dependencia (Baracaldo et al., 2018).

En aquellos casos en los que la dependencia es de grado III, se logra que la persona cuidadora exprese sentirse acompañada (esto es mencionado en las encuestas abiertas de valoración del programa) y con reducción de la sobrecarga lo que puede favorecer la permanencia en el hogar de la persona con dependencia.

La satisfacción de las personas con dependencia usuarias del programa Alkar Zaintzen se ha medido también con una entrevista de preguntas abiertas y concretas orientadas a valorar su percepción, siempre que esto fuera posible, con relación a la utilidad, calidad del servicio, beneficios para la persona cuidadora y para sí mismas, y sugerencias de mejora

El resultado medido de los últimos tres años indica un $100 \%$ de acuerdo de valoración favorable entre las 12 personas con dependencia grado II entrevistadas en relación con la utilidad del programa para ellas. Los elementos más valorados son: activación, sentirse acompañados, sentirse más alegres, mejoras en sus relaciones y aumento en la frecuencia de paseos por su barrio.

Hay también acuerdo del $100 \%$ en que el programa beneficia a sus familiares cuidadores indicando los siguientes cambios que valoran favorables: mejor salud, mayor confianza, más tranquilidad, más calma y mejor ánimo.

El $100 \%$ manifiesta querer continuar con el servicio porque se relacionan con alguien diferente a la familia, refiere mejoras en su atención, estado de ánimo y que cuentan con alguien con quien hablar "esas cosas" que no hablan con la familia, y el $100 \%$ refiere que no ha echado en falta nada en el programa. La única sugerencia que han comentado se relaciona con evaluar la posibilidad de aumentar el número de horas del programa.

\section{Año 2020: nueva realidad, nuevos retos}

La atención que se venía brindando de manera continua dio un cambio inesperado desde el 13 de marzo de 2020, día en que se decreta el estado de alarma por la covid-19 y con este el conjunto de medidas para dar frente a la expansión de la pandemia. Una de estas medidas que afectó de manera significativa el servicio de respiro fue el confinamiento total en los domicilios, ya que por diversas circunstancias ${ }^{1}$ se decidió suspender el servicio a domicilio.

Consideramos importante continuar el acompañamiento, ya que ante este aislamiento parcial era necesario mantener algún tipo de vínculo que diera soporte socioemocional a las personas cuidadoras, que en un $45,23 \%$ son personas mayores de 70 años en promedio y que cuidan en forma exclusiva a sus cónyuges, por lo que en casa estarían solos sin poder recibir visitas de hijos ni nietos.

Desde Alkar Zaintzen se decidió hacer seguimiento telefónico continuo con frecuencia semanal. En siete oportunidades se organizaron videollamadas individuales y grupales y, cuando se requería solo enviar información puntual (medidas del Gobierno, informaciones de Osakidetza y actividades de ocio digital) la comunicación se hizo por mensajes de WhatsApp. En el Gráfico 5 vemos el resumen de las comunicaciones mensuales realizadas desde el día 16 de marzo hasta el día 31 de julio.

Gráfico 5. Acompañamiento a la persona cuidadora marzo-julio 2020

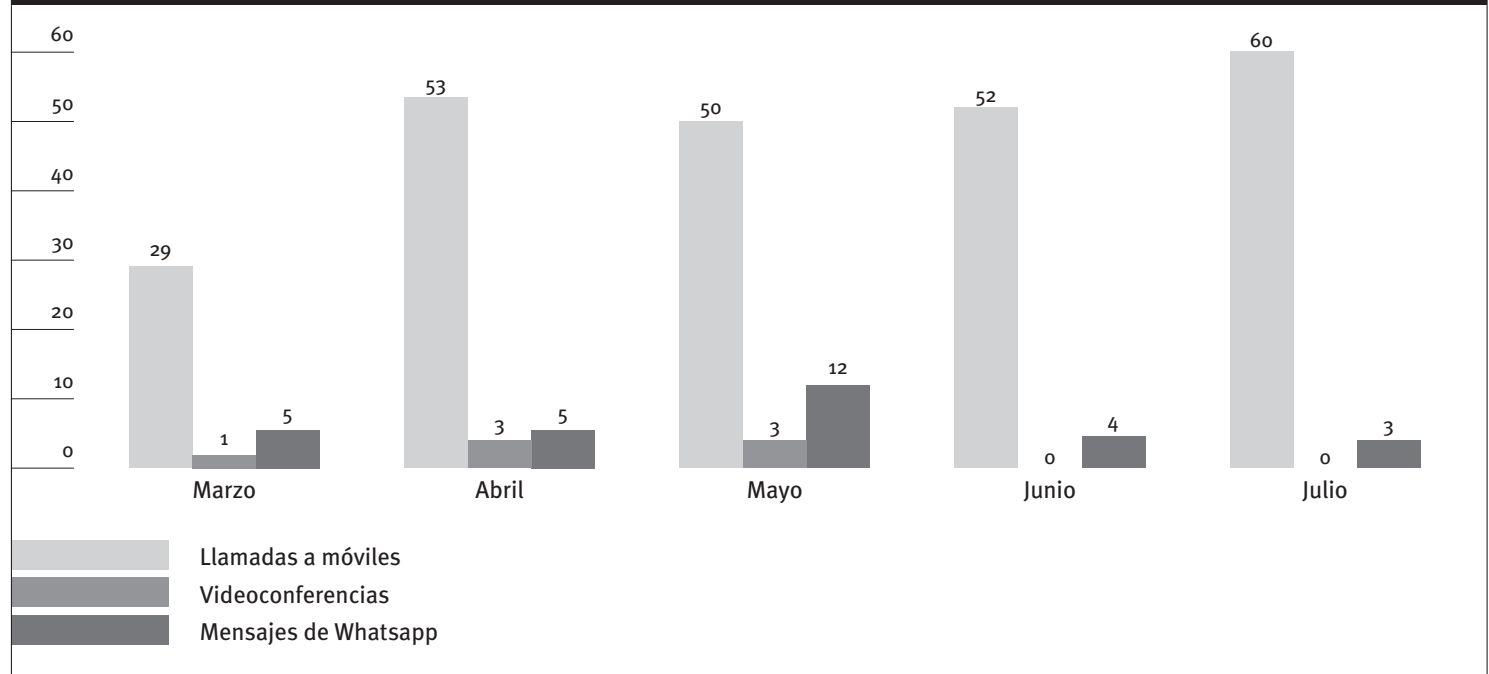

Fuente: Elaboración propia.

${ }^{1}$ Temor de las familias a la atención en casa, seguimiento de la evolución de la pandemia y adaptación de protocolos de atención a medidas sanitarias, entre otros. 
Resaltamos que todas las personas beneficiarias del programa, tanto cuidadoras como personas con dependencia, se han mantenido con buena salud general, es decir, no ha habido contagio del coronavirus.

Sin embargo, la salud relacionada con la condición de dependencia, así como el bienestar de la persona cuidadora, sí se vieron afectados en este periodo. Las medidas adicionales al confinamiento, como el cierre de los centros de día, la restricción de la atención primaria y el cierre de instituciones de atención especializada afectaron la movilidad y el funcionamiento cognitivo de aquellas personas dependientes que asisten a centros de día, así como a otras instituciones de fisioterapia o estimulación cognitiva y funcional,

La suspensión del programa de respiro afectó al área social y de movilidad de las personas en dependencia y la posibilidad de compañía o realización de actividades de no cuidado para las personas cuidadoras, esto incluso a pesar de que las mismas personas cuidadoras decidieron mantenerse con acompañamiento no presencial por el temor al contagio.

A pesar de entender la situación y elegir el no ingreso a los domicilios, las personas cuidadoras hacían énfasis en lo importante que era para ellas estar en comunicación con las responsables del programa porque mencionaron entre otros comentarios sentirse "acompañadas", "tener con quien hablar", “esperar nuestra llamada”, “agradecimiento”, "tener una persona para consultar dudas", "nos mantienen informadas de las medidas", "nos dan recomendaciones para cuidarnos", "tener con quien quejarnos de todo esto". El objetivo que nos planteamos de continuar en comunicación y que las personas cuidadoras y las personas con dependencia, se sintieran acompañadas y seguras en medio de toda esta situación, se ha cumplido satisfactoriamente.

En el mes de julio se dio inicio progresivo a la atención en los domicilios, siguiendo medidas de bioseguridad y atentos a las tendencias de contagio y desarrollo de la pandemia. Estamos atentos a los ritmos de las desescaladas, los nuevos contagios y la relativa estabilidad de la curva y nos damos cuenta de que es un momento de preguntas y reflexiones. Creemos que lo más importante es avanzar en propuestas que nos permitan pensar que modelo de cuidados de larga duración y atención a la dependencia queremos.

\section{Conclusiones}

El programa Alkar Zaintzen inicia como producto de un living $l a b^{2}$ con personas cuidadoras que

2 Espacio donde se producen procesos de innovación abierta centrada en los usuarios en donde pueden generarse nuevos modelos productivos. La novedad de los living labs es que nos ofrecen la identificaron dos necesidades cruciales para el logro de una adecuada calidad de vida, por una parte, tiempo para ellos y su autocuidado y, por otra, una buena atención para sus familiares con dependencia que les hiciera sentir seguridad.

Esto se ha logrado y así lo muestran los resultados del programa en número de personas atendidas, en la reducción de la sobrecarga de la persona cuidadora hasta niveles que van de una sobrecarga intensa a niveles medio y bajos de sobrecarga, y en la satisfacción que reportan tanto la persona cuidadora como la persona con dependencia en todos los casos en que esta puede comunicarlo. Incluso el tipo de sugerencia que mayormente refieren nos deja ver con claridad que el tiempo y tiempo de calidad es el bien más preciado, ya que nos solicitan incrementar el tiempo de atención, incrementar los días de atención, etc.

Para la persona cuidadora, las horas semanales y el acompañamiento del profesional de referencia les ha brindado tranquilidad familiar, incremento en la autonomía y aumento en su participación social (estos beneficios fueron mencionados por todas las personas cuidadoras entrevistadas esos años).

La disponibilidad de tiempo y el acompañamiento que les ha permitido planificar su autocuidado creemos que engloba el beneficio central. El tiempo valorado como un recurso equiparable al beneficio económico nos permite estar conscientes del verdadero valor de los programas de respiro en domicilio, programas que le permiten a la persona cuidadora disponer de horas de vida para sí misma incrementando su autonomía y mejorar su participación social.

Para la persona con dependencia, el programa ha incidido en el mantenimiento de su autonomía personal, con ejercicios tanto físicos como cognitivos y paseos por su comunidad, lo que le ha permitido mantener el contacto con sus vecinos y mantener actividades como tomar un café y dar paseos. Y en el caso de que la persona con dependencia está valorada como gran dependiente y tenga movilidad reducida, ha permitido mantener un espacio de cuidado y socialización en casa con personas complementarias al grupo familiar.

Hay un beneficio adicional que hemos podido valorar a raíz de la situación de emergencia de la covid-19 y es el valor de mantener la atención a la persona con dependencia en un contexto seguro y controlado, en este caso en el domicilio. Esto ha permitido monitorear tanto a la persona con dependencia como a la persona cuidadora, no presentando ningún contagio.

Todos estos beneficios reportados aportan satisfacción, pero aún quedan retos por delante;

oportunidad de tener un espacio físico para dar protagonismo a las personas en los procesos de innovación (Nieto, s.f.). 
en momentos en los que se está revalorizando y se declara la importancia de prolongar los cuidados en el domicilio, creemos que ampliar el alcance de programas de este tipo, dados los resultados, es una propuesta a valorar. Para ello se requiere una mayor inversión que garantice la disponibilidad de recursos especializados para la familia y la atención a la persona con dependencia favoreciendo su permanencia en su domicilio y en su comunidad, pero profesionalizando esos cuidados y no dejando una vez más la carga solo a las familias.

Obviamente, la respuesta no está solo en programas de respiro en el domicilio y ampliar su alcance. Se trata de hacer una revisión innovadora, revisar el propio modelo de cuidados de larga duración, su gestión, la visión que tenemos de este en la sociedad y avanzar siguiendo lo propuesto por Dolors Comas (2020) a una democratización que promueva el reconocimiento del cuidado y su centralidad, que socialice las responsabilidades del cuidado como problema social y político, potenciar los servicios públicos y articularlos con las cuestiones comunitarias, repartir el cuidado entre hombres y mujeres teniendo en cuenta los derechos y demandas de las personas que requieren los cuidados.

Finalmente cerramos tomando la propuesta del SIIS Centro de Documentación y Estudios (2020) en relación con la necesidad de dar pasos para desarrollar modelos que faciliten la personalización de la atención frente al fordismo asistencial, la búsqueda del bienestar y de una vida con sentido como objetivo prioritario frente al énfasis en la estandarización de los procesos y de la atención, buscando paralelamente ideas para optimizar el sistema de financiación de este sistema. Y nosotros agregaríamos la necesidad de dar a conocer las buenas prácticas que se están realizando para integrarlas a un sistema que promueva la innovación en el área de los cuidados de larga duración lo que nos motivó a presentar nuestra experiencia. 


\section{Referencias bibliográficas}

ARROYO LEWIN, M.A. y BERMÚDEZ GARCÍA, J.A. (2020): "El acompañamiento ignaciano en el siglo XXl”, Revista Ensayos Pedagógicos, vol. XV, $\mathrm{n}$ 을, 〈https://doi.org/10.15359/rep.15-1.7〉.

ÁVILA, B. (2018): Acompañamiento Pastoral, Madrid, GP Actualidad.

BARACALDO, H.; NARANJO, A. y MEDINA, V. (2018): “Nivel de dependencia funcional de personas mayores institucionalizadas en centros de bienestar de Floridablanca", Gerokomos, vol. 30, no 4, pp.163-166, « http://gerokomos.com/ revistas/>.

BROVELLI, K. (2019): “El cuidado: una actividad indispensable pero invisible", en GUERRERO, G.N.; RAMACCIOTTI, K. y ZANGARO, M. (comps.), Los derroteros del cuidado, Bernal, Universidad Nacional de Quilmes, pp. 31-44.

- (2015): “Cuando el cuidado no es un asunto de mujeres. Organización de los cuidados por parte de personas en situación de vulnerabilidad psicosocial”, Revista Argentina de Terapia Ocupacional, Año 1, nํㅜ 1, pp. 20-27.

CARRAL, C. (2015) "La responsabilidad de cuidar a personas en situación de dependencia, una propuesta teórica para la elaboración de políticas públicas", Encrucijada. Revista Crítica de Ciencias Sociales, vol. 10, a1005, «https:// recyt.fecyt.es/index.php/encrucijadas/article/ view/79050>.

CARRASCO C.; BORDERÍAS, C. y TORNS, T. (2011): "Introducción. El trabajo de cuidados: antecedentes históricos y debates actuales", en CARRASCO, C.; BORDERÍAS, C. y TORNS, T. (eds.), El trabajo de cuidados: historia, teoría y políticas, Colección Economía Crítica y Ecologismo Social, Madrid, Catarata, pp. 13-95.
CARRASCO, C. (2014-2015): "El cuidado como bien relacional: hacia posibles indicadores", Papeles de Relaciones Ecosociales y Cambio Global, no 128 , págs. 49-60.

CENTRO DE INVESTIGACIONES SOCIOLÓGICAS (2014): Cuidados a Dependientes. Serie Estudios, núm. 3009, 〈http://www.cis.es/cis/opencm/ES/1 encuestas/estudios/ver.jsp?estudio $=14078$.

COMAS D’ARGEMIR, D. (2020): “Ética del cuidado”, en Curso de verano El modelo de cuidados a las personas mayores: ¿qué nos ha enseñado la crisis del COVID-19?, Universidad Pública de Navarra, «https://www.youtube.com/ watch? $v=$ W43LEXe7SbQ $>$.

D’HYVER, C. (2017): “Valoración geriátrica integral”, Revista de la Facultad de Medicina de la UNAM, vol. 60, no 3 , 〈https://www.medigraphic.com/cgi-bin/ new/contenido.cgi?IDPUBLICACION=7068>.

DIPUTACIÓN FORAL DE BIZKAIA (2007) Boletín Oficial de Bizkaia, núm. 14, martes, 19 de enero, 〈http:// www.revista.terapia-ocupacional.org.ar/ volumen\%201.html>.

- (2014): Memorias del Departamento de Acción Social, <https://www.bizkaia.eus/ home2/Temas/DetalleTema.asp?Tem_ Codigo $=7058 \&$ idioma $=$ CA\&dpto biz=3\&codpath_biz=3\%7C7058>.

- (2020): "Rementeria: Este virus no va a vencernos". Unidad de apoyo al Diputado General, 28 septiembre, <https://web.bizkaia. eus/es/web/area-de-prensa/noticias/-/ news/detailView/21217?_News_ redirect $=\% 2$ Fes $\% 2$ Fweb\%2Farea-de-prensa〉.

DURÁN, M.A. (2017): “Tiempo y calidad de vida”, Boletín Ecos 37, 〈www.fuhem.es/ecosocial〉. 
DWYER, J.; LEE, G.; JANKOWSKI, T. (1994): “Reciprocity Elder Satisfaction, and Caregiver Stress and Burden: The Exchange of Aid in the Family Caregiving Relationship", Journal of Marriage and the Family, vol. 56, no 1, pp. 35-43.

EL CORREO (2020): "Bizkaia desarrolla nuevos programas de respiro para cuidadores de personas dependientes", El Correo, 08 de octubre, <https://www.elcorreo.com/ vizcaya/20120628/local/bizkaia-personasdependencia-201206281540.html?.

EZQUERRA, S. (2012): “Crisis de los cuidados y crisis sistémica: la reproducción como pilar de la economía llamada real", Investigaciones Feministas, vol. 2, pp.175-194.

FANTOVA, F. (2018): "Los cuidados como eje para la transformación de las políticas sociales”, Documentación Social, no 187, págs. 7189, 〈https://www.researchgate.net/ publication/328041833>.

- (2015): “Crisis de los cuidados y servicios sociales", Zerbitzuan, no 6o, pp.47-62, 〈https://doi. org/10.5569/1134-714.60.04>.

FERNÁNDEZ CARRO, C. (2020): “¿Quiénes, cómo y por qué?" Cambios y continuidades en el cuidado informal a personas en edades avanzadas", en Curso de Verano El modelo de cuidados a las personas mayores: ¿qué nos ha enseñado la crisis del COVID-19?, Universidad Pública de Navarra, <https://www.youtube.com/ watch? $v=$ W43LEXe7SbQ $>$.

FERNÁNDEZ, E.; y ESTÉVEZ, M. (2013): “La valoración geriátrica integral en el anciano frágil hospitalizado: revisión sistemática", Gerokomos, vol. 24, nํㅜ 1 .

FLORES, E.; RIVAS, E.; y SEGUEL, F. (2012): “Nivel de sobrecarga en el desempeño del rol del cuidador familiar de adulto mayor con dependencia severa", Ciencia y Enfermería, vol. 18, n- 1, pp. 29-41, < https://scielo.conicyt. $\mathrm{cl} /$ scielo.php?script $=$ sci_issuetoc $\&$ pid $=0717-$ 955320120001\&lng=es\&nrm=iso>.

GOBIERNO DE ESPAÑA (2006) “Ley 39/2006, de 14 de diciembre, de Promoción de la Autonomía Personal y Atención a las Personas en Situación de Dependencia”, Boletín Oficial del Estado, no 299, 15-12-2006, pp. 44.14244.156, <http://www.boe.es/buscar/doc. php?id=BOE-A-2006-21990>

GOBIERNO VASCO (2008): Ley 12/2008, de 5 de diciembre, de Servicios Sociales, Boletín Oficial del País Vasco, no 246, 24-12-2008, 〈https://www. euskadi.eus/y22-bopv/es/p43aBOPVWebWar/ VerParalelo.do?cd2008007143〉.

HOCHSCHILD, A. (2012): The Managed Heart; Commercialization of Human Feeling, Berkeley, University of California Press.

IMSERSO (2012): Guía de prestaciones, Madrid.

INSTITUTO NACIONAL DE ESTADÍSTICA (2010): Boletín Informativo del Instituto Nacional de Estadística. Encuesta de empleo del tiempo.

LEÓN, C. (2014): "Secuencias del Desarrollo Infantil”, Caracas, Ediciones UCAB.

LOWNEY, C. (2004): “El Liderazgo al estilo de los jesuitas", Bogotá, Grupo Editorial Norma, Bogotá, Grupo editorial Norma.
MARTÍNEZ RUPÉRES, M. (2013): “El arte de acompañar/NOS. Procesos y metodologías", colección La Acción Social, Cuadernos de Formación, no 63. Madrid, Cáritas Española

MESTO, A. (2018): “Interdependencia y Crisis de cuidados” [Trabajo fin de Máster], Madrid Universidad Carlos III de Madrid, « https://e-archivo.uczm. es/handle/10016/27931>.

MONTENEGRO, L.; SALAZAR, C.; DE LA PUENTE, C.; GÓMEZ, A.; y RAMÍREZ, E. (2009): “Aplicación de la evaluación geriátrica integral en los problemas sociales de adultos mayores", Acta médica peruana, vol. $26, \mathrm{n}-3$.

MORÉ, P. (2020): “Cuidados y crisis del coronavirus: el trabajo invisible que sostiene la vida”, Revista Española de Sociología, vol. 29, nํㅜ 3, pp. 737745, <https://ruc.udc.es/dspace/bitstream/ handle/2183/26488/More_P_2020_Cuidados_ crisis.pdf .

NIETO, C. (s.f.): "Los living labs en los procesos de innovación”, Designthinking.gal, <https:// designthinking.gal/los-living-labs-en-losprocesos-de-innovacion/s,

ORUE AUZOLANA FUNDAZIOA (2013): Documentos justificativos Alkar Zaintzen: Programa de respiro a personas cuidadoras, AmorebietaEtxano.

PÉREZ, R.; ÁLVAREZ, G.; MARTÍNEZ, B.; VALDIVIA, C.; BORROTO, C.; PEDRAZA, N. (2017): "El síndrome del cuidador en cuidadores principales de ancianos con demencia Alzhéimer", Gaceta Médica Espirituana, vol.19, $\mathrm{n} \cap 1$.

RAMÍREZ CARRO, R. (2012): La vida (buena) como riqueza de los pueblos. Hacia una socioecología política del tiempo, IAEN, Quito.

RAMÍrEZ GARCÍA, G. et al. (2004): El Acompañamiento Personal y Grupal "Cura Personalis", Colegio San Ignacio ediciones. Bogotá.

RTVE.ES (2020): “Coronavirus: Radiografía del coronavirus en residencias de ancianos: más de 20.900 muertos con COVID-19 o síntomas compatibles", RTVE.es, 24 de octubre, <https:// www.rtve.es/noticias/20201014/radiografiadel-coronavirus-residencias-ancianosespana/2011609.shtmls.

RUBIO, I. y MADARIAGA, O. (2013): "Los servicios de asistencia a los cuidadores familiares de personas mayores dependientes en la provincia de Bizkaia”, IV Congreso red Española de Política Social, pp. 933-942, 〈https://dialnet. unirioja.es $/$ servlet $/$ articulo? codigo $=5723701$.

SIIS CENTRO DE DOCUMENTACIÓN Y ESTUDIOS (2020): "Algunas pistas para la mejora del sistema de atención a la dependencia en España", Zerbitzuan, $\mathrm{n}^{\circ} \mathbf{0}$ 72, págs. 77-90, <https://doi. org/10.5569/1134-7147.72.06>.

VELASCO, E. (2018): “Acompañamiento Ignaciano: Escuchar para construir”, en ZATYRKA, A.: Conferencia Diálogos sobre el acompañamiento al estilo ignaciano, CRUCE, Universidad Jesuita de Guadalajara, <https://cruce.iteso.mx/ acompanamiento-ignaciano-escuchar-paraconstruir/s.

VILLAMAR, P. (2014): “Presencia del 'síndrome del cuidador' en cuidadores de pacientes con esquizofrenia 
ingresados en el Instituto de Neurociencias de la JBG" [tesis grado psicología], Ecuador, Universidad de Guayaquil, Facultad de Ciencias Psicológicas, 〈http://repositorio.ug.edu. ec/bitstream/redug/6283/1/TESIS\%20 SINDROME\%20DEL\%20CUIDADOR.pdf〉.
WILSON, H (1989): "Family caregiving for a relative with Alzheimer's Dementia: coping with negative choices", Nursing Research, vol. 38, pp. 94-98. 